\title{
Validity of subjective assessment of changes in respiratory health status: a 30 year epidemiological study of workers in Paris
}

\author{
F. Kauffmann*, I. Annesi*, J. Chwalow**
}

Validity of subjective assessment of changes in respiratory health status: a 30 year epidemiological study of workers in Paris. F. Kauffmann, I. Annesi, J. Chwalow. (CERS Journals Ltd 1997.

ABSTRACT: The validity of scales used for subjective assessment of health, particularly transitional indices, is under discussion. The aim of the present study was to assess the concurrent and predictive validity of a simple estimate of long-term subjective assessment of respiratory health changes.

A longitudinal study of 915 workers was conducted over 30 yrs, with both retrospective self-assessment of respiratory health changes and objective measurements of spirometric values $\mathbf{1 2}$ yrs apart. An assessment of the reason for death during the subsequent 20 yrs was performed.

Subjective assessment of respiratory deterioration over 12 yrs was significantly related to both cross-sectional lung function values and longitudinal lung function changes (forced expiratory volume in one second (FEV1) decline), an association which remained after adjustment for FEV1 level. It was also related to the same risk factors as decline in FEV1 (smoking, occupational exposure). Self-evaluation of respiratory deterioration was significantly predictive of death from all causes, with the highest (but nonsignificant) rate ratio for respiratory causes. Asthmatics exhibited greater long-term variability (objective and subjective) than nonasthmatics. Independent of dyspnoea, self-assessment of respiratory health deterioration was significantly related to FEV1.

Subjective assessment of long-term changes in respiratory health provides valid information.

Eur Respir J 1997; 10: 2508-2514.

The acceptance of self-perception of health status is relatively recent [1-4]. The validity of perceived health measures (which are the basis of items included in health-related quality of life scales) is a matter of discussion as objective measures of the same or highly related phenomenon are rarely available or relevant [5-7]. Responsiveness, i.e. the ability to detect changes between repeated measurements, is an important quality [2, $6]$. Transitional indices $[6,8-10]$ (i.e. those designed to directly assess perceived changes over time) are rarely used. Such indices are retrospectively assessed at the end of the period under study. The duration for which change is assessed is often short (less than $1 \mathrm{yr}$ ), and the interpretation of such transitional indices can be hampered by potential recall bias. Valid long-term assessment of respiratory health changes may be of interest for both epidemiological research and clinical practice. No study has assessed long-term perceived respiratory changes.

The general aim of the present study was to assess the concurrent and predictive validity of a simple estimate of long-term subjective assessment of respiratory health changes using objective criteria recorded in the same longitudinal survey conducted in a working population. The specific aims were to assess whether retrospective subjective assessment of changes at 12 yrs was
*INSERM, Epidemiological Research Unit INSERM U169, Villejuif, France. **INSERM Clinical and Epidemiological Research Unit INSERM, U21, Villejuif, France.

Correspondence: F. Kauffmann INSERM U169

16 ave P.V. Couturier

F-94807 Villejuif Cédex

France

Keywords: Asthma

dyspnoea

longitudinal

mortality

perceived health

spirometry

Received: January 61997

Accepted after revision July 241997 related to known risk factors of forced expiratory volume in one second (FEV1) decline, 12 yr FEV1 decline itself, a history of asthma, and $20 \mathrm{yr}$ mortality data.

\section{Methods}

The subjects in the study were enrolled in a longitudinal study on the risk factors of chronic obstructive pulmonary diseases with two cross-sectional surveys in 1960 and 1972. A study of survival up to 1992 has been performed. The detailed protocol has been described elsewhere [11].

In a first survey conducted in 1960-1961, 1,474 men born in France, aged 30-59 yrs, working in 11 factories (metallurgy, chemistry, printing and flour milling) in the Paris area were interviewed about their symptoms (but without a specific question on asthma) and smoking habits. Occupational exposure to physical or chemical hazards was assessed for each work place [12].

At the time of the second survey, 1972-1973, 1,248 subjects were still living, 1,073 , i.e. $86 \%$, were re-interviewed, most of them (844) at the factory or at a medical centre, some of them (144) at home and the remainder (85) by mailed questionnaire. Men completed the BMRC/ ECSC (British Medical Research Council/European Coal 
and Steel community) questionnaire [13] about symptoms and smoking habits. Dyspnoea was recorded in five levels (grade 1, none; grade 2, whilst walking up a slight hill; grade 3, walking with other people of own age on level ground; grade 4, at own pace on level ground; grade 5 , at rest). The BMRC/ECSC question on asthma is "Have you ever had attacks of breathlessness with wheezing (asthma attacks)?" Subjects were classified as having current asthma (last attack within the last year), past asthma or no asthma. Chronic bronchitis was defined by the presence of phlegm for at least 3 months each year. Except for those who answered the mailed questionnaire, all subjects were interviewed about their individual perception of respiratory health changes with the following question: "Overall, since 1960-1961, do you think that your bronchi or respiratory status has changed (independent of the "normal effect of ageing")?" If yes, they were asked "Has it improved? Has it deteriorated?" Ninety three percent answered the question (which corresponds to $73 \%$ of the original living subjects). Two dichotomous variables were derived from these questions. "Feels worse" was defined as having deteriorated compared to the others. Among those without deterioration, "feels better" was defined as having improved compared to those with no change.

Twelve year FEV1 decline and self-assessment of respiratory health changes were available for 827 men. Poor tracings were included in the analysis, as spirometric test failure may correspond to a particular set of subjects [14] and because the present study concerned a pragmatic [15], rather than an explicative issue in a real setting. In any case, lack of spirometric tracings and poor tracings were unrelated to "feels worse" or "feels better". Figures without and with the exclusion of poor tracings are provided for the most important results or in the few cases where results differ. Overall, exclusion of poor tracings did not affect the conclusions. For each man, 1960 and 1972 FEV1 values were adjusted for age and height by using linear regression [16] in all men and standardized residuals (mean $\pm \mathrm{SD}=0 \pm 1$ ). The $\mathrm{r}^{2}$ values for the linear regressions were 0.40 in 1960 and 0.36 in 1972 . Twelve year $\mathrm{FEV} 1$ slope $\left(\mathrm{mL} \cdot \mathrm{yr}^{-1}\right)$ was calculated as:

$$
\begin{aligned}
& 12 \times(\text { FEV } 1 \text { in } 1960-\text { FEV1 in 1972)/ } \\
& \text { (months between the two surveys) }
\end{aligned}
$$

In order to assess whether "feels worse" was related to FEV1 decline independent of its association with the current level, the association of "feels worse" with FEV1 decline was analysed before and after adjustment for FEV1 level, which from the epidemiological point of view is the final FEV1. Actually, when a change is assessed with only two points, it relates to the final (as well as the initial) value because of the phenomenon of regression towards the mean [17]. Therefore, adjustment was performed considering the average of the initial and final values. Such adjustment was similar to that performed by FLETCHER et al. [18] and in our previous analyses $[11,12,19]$. Subjects were also classified as having chronic airflow limitation in 1972. Those considered as obstructed were those with an FEV1 percentage predicted value less than or equal to the ECSC reference values less or equal to the cut-offs of $75 \%$ and $65 \%$ [20]. Interviewers were blinded regarding lung function results, as 1972 lung function was assessed after the questionnaire.

As of December 31, 1992 vital status was available for 874 subjects (4\% with status unknown); 412 (47.1\%) were dead. In France, the individual cause of death is not available through death certificates alone. Therefore, they were estimated by cross-referencing two data bases: 1) causes of death throughout France (available for the deaths that occurred up to the end of 1991), which includes dates and places of birth and death; and 2) dates and places of birth and death of the subjects under study. To respect the laws on confidentiality, the cross-referencing was performed independently of the authors. Causes of death were determined for 344 deaths, i.e. $88 \%$ of the 389 men who had died by December 31, 1991.

Statistical analyses included Chi-squared $\left(\chi^{2}\right)$, analysis of variance and linear regression [21], and Cox proportional-hazards regression models for survival analysis [22, 23].

\section{Results}

\section{Concurrent validity}

Among the 915 men who answered the question on perceived changes, $22 \%$ reported deterioration and $5 \%$ improvement. Subjective assessment of deterioration was

Table 1. - Relationships of subjective assessment of respiratory changes between 1960 and 1972 to spirometric

\begin{tabular}{|c|c|c|c|c|c|c|}
\hline & $\begin{array}{c}\text { Subjects } \\
\mathrm{n}\end{array}$ & $\begin{array}{c}\text { Age in } 1972 \\
\text { yrs }\end{array}$ & $\begin{array}{l}1960 \mathrm{FEV} 1 \\
\text { score }\end{array}$ & $\begin{array}{l}1972 \mathrm{FEV} 1 \\
\text { score }\end{array}$ & $\begin{array}{l}\text { 1960-1972 } \\
\text { FEV1/H }{ }^{3} \text { level } \\
\mathrm{cL} \cdot \mathrm{m}^{-3}\end{array}$ & $\begin{array}{c}\text { 1960-1972 } \\
\text { FEV1 decline } \\
\text { mL·yr }\end{array}$ \\
\hline \multicolumn{7}{|c|}{ "Feels worse" } \\
\hline No & 648 & $54.1 \pm 8.4$ & $0.05 \pm 0.97$ & $0.10 \pm 0.93$ & $67.5 \pm 11.7$ & $40.8 \pm 35.4$ \\
\hline Yes & 179 & $52.9 \pm 8.2$ & $-0.19 \pm 1.07$ & $-0.36 \pm 1.17$ & $64.1 \pm 13.9$ & $54.4 \pm 40.8$ \\
\hline p-value* & & 0.09 & 0.004 & $<0.001$ & $<0.001$ & $<0.001$ \\
\hline \multicolumn{7}{|c|}{ "Feels better" } \\
\hline No & 603 & $54.1 \pm 8.4$ & $0.08 \pm 0.94$ & $0.13 \pm 0.91$ & $67.8 \pm 11.3$ & $40.7 \pm 35.4$ \\
\hline Yes & 45 & $54.0 \pm 8.6$ & $-0.33 \pm 1.27$ & $-0.29 \pm 1.08$ & $63.4 \pm 15.2$ & $42.1 \pm 36.2$ \\
\hline p-value* & & & 0.006 & 0.003 & 0.01 & \\
\hline
\end{tabular}
variables

Values are mean \pm SD. Forced expiratory volume in one second (FEV1) scores are age and height-adjusted using linear regression on age and height for the whole sample. FEV1/height $\left(\mathrm{H}^{3}\right)$ level is the midpoint of $\mathrm{FEV} 1 / \mathrm{H}^{3}$ during the study period. Standard deviations of unadjusted FEV1 in 1960 and 1972 were 67 and $75 \mathrm{~mL}$ respectively. After adjustment for age and height, residual standard deviations were 51 and $60 \mathrm{~mL}$. Therefore, differences in 1960 and in 1972 between those with and without reported deterioration of 0.24 and 0.46 in FEV1 score correspond in absolute terms to $0.24 \times 51=12 \mathrm{~mL}$ and $0.46 \times 60=28 \mathrm{~mL}$, respectively. *: p-values are for comparison of No and Yes values. 
related to objective measures. "Feels worse" was significantly related to lower FEV1 scores in 1960 with a stronger relationship in 1972 (table 1). Significantly steeper FEV1 declines were observed among those who reported deterioration, compared to other subjects (table 1). Those who reported deterioration were approximately $1 \mathrm{yr}$ younger than the other men. Thus, subjects who answered the question on self-assessment of respiratory changes were able (as requested) to "correct for the normal effect of ageing". By contrast, the 73 men who did not answer the question were 10 yrs older than the 915 responders $(64.2 \pm 6.3$ versus $54.1 \pm 8.4 ; p<0.001)$. FEV1 scores were significantly lower at both surveys in those who reported improvement than in those with-

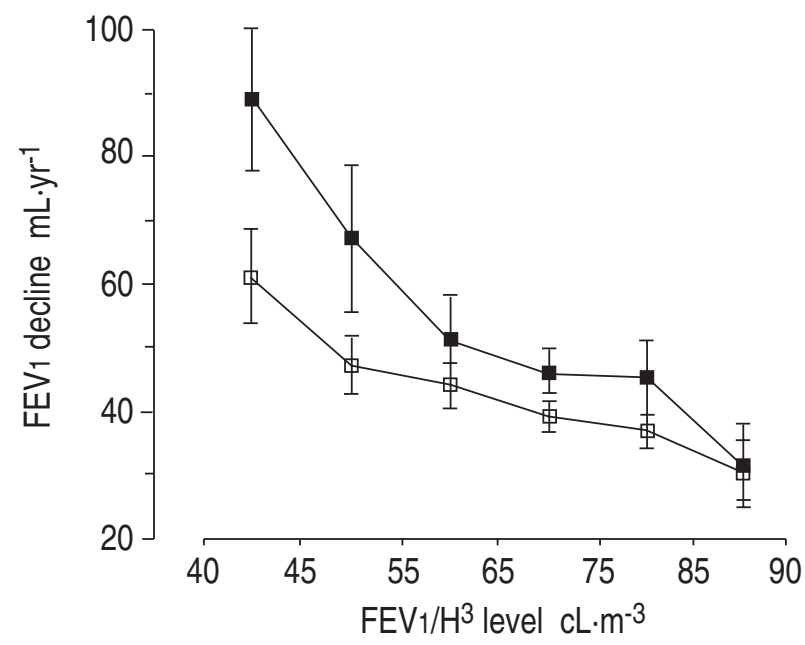

Fig. 1. - Twelve year forced expiratory volume in one second (FEV1) decline according to self-assessment of respiratory deterioration and $\mathrm{FEV} 1 /$ height $\left(\mathrm{H}^{3}\right)$ level. Values are given as mean \pm SEM, adjusted for $\mathrm{FEV}_{1} / \mathrm{H}^{3}$ midpoint level (see methods). FEV 1 decline values were 52.9 versus $41.2 \mathrm{~mL} \cdot \mathrm{yr}^{-1}$ for those who reported deterioration versus other men. The p-values were $<0.001$ in models adjusting on $\mathrm{FEV} 1 / \mathrm{H}^{3}$ as a quantitative variable or considering classes $(<45$, $45-54,55-64,65-74,75-84, \geq 85 \mathrm{cL} \cdot \mathrm{m}^{-3}$ ) as depicted here (general linear model for unbalanced analysis of variance). $\square$ : did not report deterioration; $\mathbf{\square}$ : did report deterioration. out change. FEV1 decline was unrelated to "feels better".

Subjects who responded that they were "feeling worse" in 1972 still had a significantly $(\mathrm{p}<0.001)$ steeper FEV1 decline after adjustment for FEV1 levels, considering either FEV1 level as a quantitative variable or considering classes of FEV1 level, as represented in figure 1. Subjective assessment of deterioration over 12 yrs was, therefore, related to objective assessment of deterioration over $12 \mathrm{yrs}$, and not only to health status at the time of interview. The association of "feels worse" with FEV1 decline persisted after exclusion of those with a history of asthma ( $8 \%$ of the subjects) and was unchanged by taking age into account. Exclusion of poor tracings gave similar results (FEV1 decline adjusted for FEV1 level was $55.8 \mathrm{~mL} \cdot \mathrm{yr}^{-1}$ versus $43.5 \mathrm{~mL} \cdot \mathrm{yr}^{-1}$ for those with and without "feeling worse"; $\mathrm{p}=0.001$ ).

\section{Risk factors (smoking and occupational exposure)}

Tobacco consumption was related to both objective and subjective assessment of deterioration in health status (table 2). Occupational exposure was related to both FEV1 decline $(\mathrm{p}<0.001)$ and to a lesser extent to "feels worse" (odds ratio $=1.41,95 \%$ confidence interval $(\mathrm{CI})$ 0.98-2.03). "Feeling better" was negatively related to occupational exposure, with an association of borderline significance (odds ratio $=0.60,95 \%$ CI $0.33-1.10$ ). When excluding poor tracings, occupational exposure was no longer associated with "feels worse" (odds ratio $=1.09,95 \%$ CI $0.71-1.65)$, but the association was unchanged for "feeling better" (odds ratio $=0.56,95 \%$ CI 0.28-1.13). Quitting smoking between the two surveys was significantly related to reported improvement (odds ratio $=5.28,95 \%$ CI 2.60-10.74), with an even higher odds ratio when excluding poor tracings $(8.31,95 \% \mathrm{CI}$ 3.82-18.07). However, no significant difference was observed for FEV1 decline between those who quit smoking and those who remained current smokers. "Feels

Table 2. - Relationships of subjective assessment of respiratory changes and spirometric variables to smoking habits and occupational exposure

\begin{tabular}{|c|c|c|c|c|c|c|c|c|}
\hline & $\begin{array}{l}\text { Subjects } \\
\mathrm{n}\end{array}$ & $\begin{array}{l}\text { Age in } \\
1972 \\
\text { yrs }\end{array}$ & $\begin{array}{l}1960 \mathrm{FEV} 1 \\
\text { score }\end{array}$ & $\begin{array}{l}1972 \mathrm{FEV} 1 \\
\text { score }\end{array}$ & $\begin{array}{c}\text { 1960-1972 } \\
\mathrm{FEV} 1 / \mathrm{H}^{3} \text { level } \\
\mathrm{cL} \cdot \mathrm{m}^{-3}\end{array}$ & $\begin{array}{l}\text { 1960-1972 } \\
\text { FEV1 decline } \\
\text { mL·yr }{ }^{-1}\end{array}$ & $\begin{array}{l}\text { "Feels } \\
\text { worse" } \\
\%\end{array}$ & $\begin{array}{l}\text { "Feels } \\
\text { better" } \\
\%\end{array}$ \\
\hline \multicolumn{9}{|c|}{ Smoking habits in 1960} \\
\hline Nonsmokers & 124 & $54.6 \pm 8.7$ & $0.24 \pm 0.93$ & $0.38 \pm 0.87$ & $69.6 \pm 11.5$ & $35.0 \pm 38.0$ & 12.1 & 7.3 \\
\hline Exsmokers & 91 & $56.2 \pm 8.6$ & $-0.05 \pm 1.12$ & $0.11 \pm 1.00$ & $65.5 \pm 14.6$ & $36.3 \pm 37.8$ & 25.3 & 7.4 \\
\hline Moderate smokers & 361 & $54.0 \pm 8.3$ & $-0.02 \pm 1.00$ & $-0.06 \pm 1.03$ & $66.2 \pm 12.1$ & $45.6 \pm 38.5$ & 21.1 & 7.4 \\
\hline $\begin{array}{l}\text { Heavy smokers } \\
\text { p-value }\end{array}$ & 249 & $\begin{array}{c}52.3 \pm 8.0 \\
0.001\end{array}$ & $\begin{array}{c}-0.05 \pm 0.96 \\
0.05\end{array}$ & $\begin{array}{c}-0.14 \pm 0.98 \\
0.001\end{array}$ & $\begin{array}{c}66.8 \pm 11.6 \\
0.04\end{array}$ & $\begin{array}{c}48.1 \pm 33.1 \\
0.002\end{array}$ & $\begin{array}{l}25.7 \\
0.02\end{array}$ & 6.0 \\
\hline \multicolumn{9}{|c|}{$\begin{array}{l}\text { Quit smoking between } \\
1960 \text { and } 1972 \text { among } \\
1960 \text { smokers }\end{array}$} \\
\hline No & 499 & $52.8 \pm 8.1$ & $-0.02 \pm 0.95$ & $-0.07 \pm 0.99$ & $67.0 \pm 11.8$ & $46.1 \pm 35.6$ & 23.3 & 3.9 \\
\hline $\begin{array}{l}\text { Yes } \\
\text { p-value }\end{array}$ & 103 & $\begin{array}{c}55.8 \pm 8.4 \\
0.001\end{array}$ & $-0.12 \pm 1.04$ & $-0.19 \pm 1.11$ & $\begin{array}{c}64.0 \pm 12.8 \\
0.04\end{array}$ & $49.4 \pm 41.2$ & 23.3 & $\begin{array}{c}17.7 \\
0.001\end{array}$ \\
\hline \multicolumn{9}{|c|}{$\begin{array}{l}\text { Occupational exposure } \\
\text { in } 1960\end{array}$} \\
\hline No & 279 & $54.8 \pm 8.9$ & $-0.04 \pm 1.06$ & $0.08 \pm 0.98$ & $66.1 \pm 12.6$ & $37.5 \pm 33.3$ & 17.9 & 9.2 \\
\hline Yes & 548 & $53.4 \pm 8.1$ & $0.02 \pm 0.97$ & $-0.04 \pm 1.01$ & $67.1 \pm 12.0$ & $46.9 \pm 38.5$ & 23.5 & 5.7 \\
\hline p-value & & 0.02 & & 0.10 & & 0.001 & 0.06 & 0.10 \\
\hline
\end{tabular}

Values are mean \pm SD. FEV1 scores are age and height-adjusted using linear regression on age and height on the whole sample. The p-values refer to analyses of variance on the scores. FEV $1 / \mathrm{H}^{3}$ level is the midpoint of $\mathrm{FEV} 1 / \mathrm{H}^{3}$ during the study period. For definitions of abbreviations see legend to table 1 . 
worse" was significantly related to quitting smoking only if it had occurred within the last year, whereas "feels better" related to quitting smoking independent of the time elapsed since quitting. The association of quitting smoking with "feels better" remained after exclusion of asthmatics and held true among those who did not report quitting smoking for respiratory reasons. Socio-occupational class was unrelated to "feels worse" or "feels better" ("feels worse" was reported by 21.6, $17.7,22.2$ and $22.0 \%$ of professionals, employees, qualified and unqualified manual workers, respectively).

\section{Asthma}

Eight percent of the subjects reported a history of asthma, $4 \%$ with current and $4 \%$ with only past asthma (assessed retrospectively according to the 1972 questionnaire). Asthmatics had significantly lower FEV1 level, (FEV1 scores were -0.74 versus 0.06 in 1960 and -0.85 versus 0.08 in $1972 ; \mathrm{p}<0.001$ ) and a steeper FEV1 decline than nonasthmatics $\left(57.3 \mathrm{~mL} \cdot \mathrm{yr}^{-1}\right.$ versus $42.3 \mathrm{~mL}$. $\left.\mathrm{yr}^{-1} ; \mathrm{p}=0.001\right)$. Asthmatics were significantly older than nonasthmatics $(56.4 \pm 8.1$ versus $53.6 \pm 8.4 ; \mathrm{p}=0.007)$. The association of asthma with FEV1 decline was unchanged by taking age into account.

Greater functional variability was evidenced by the significantly larger variance of FEV1 decline in asthmatics compared to nonasthmatics $\left(\mathrm{SD}=51.0 \mathrm{~mL} \cdot \mathrm{yr}^{-1}\right.$ versus $35.2 \mathrm{~mL} \cdot \mathrm{yr}^{-1} ; \mathrm{p}<0.001$ ). Long-term perceived variability was demonstrated by a significant association of asthma with both "feels worse" (odds ratio $=3.06$, 95\% CI 1.87-5.00) and "feels better" (odds ratio = 7.74; 95\% CI 3.98-15.07), associations which remained significant (odds ratios were 2.21 and 6.41, respectively) after taking into account FEV1 scores at the time of interview (final FEV1). Functional and perceived long-term variability were related (fig. 2). Among subjects with past or current asthma, those with a self-reported improvement had the least steep FEV1 decline. Subjects with

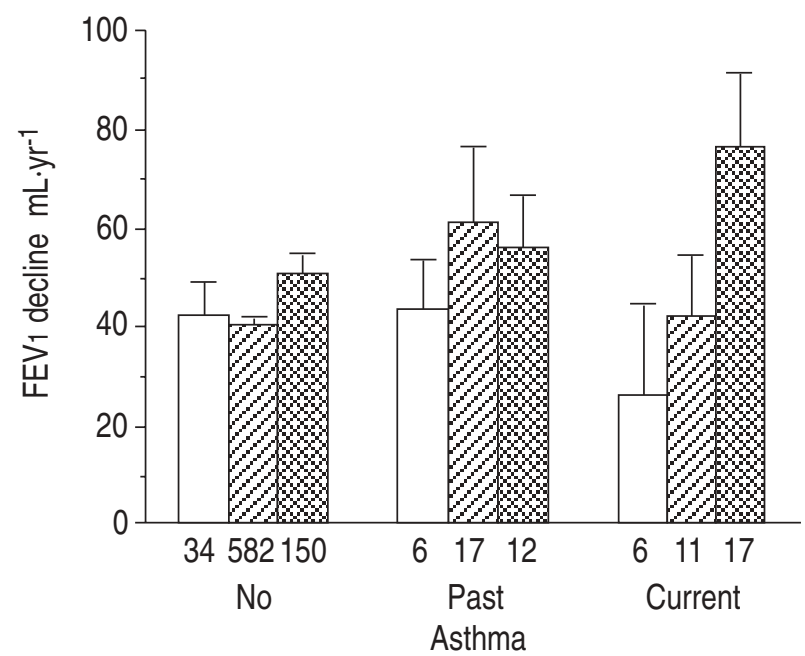

Fig. 2. - Twelve year forced expiratory volume in one second (FEV1) decline according to self-assessment of respiratory changes and asthma. The p-values in a model with two main effects subjective change and asthma and the interaction term subjective changexasthma were 0.01 for change, 0.43 for asthma and 0.10 for the interaction term. Values printed on the abscissa are the numbers of subjects. feels better; $\square$ : no change; $\square$ : feels worse. current asthma who reported deterioration had the steepest 12 yr FEV1 decline. Asthmatics were more often unable to answer the question (odds ratio $=2.47,95 \% \mathrm{CI}$ 1.35-4.55). This relationship was statistically significant. Those subjects who did not answer had lung function values similar to those who did. After exclusion of subjects with poor tracings, associations of subjective change according to asthmatic status remained significant and similar to those presented in figure 2. For those with no asthma, FEV1 decline values, for those feeling better, similar or worse were 45,43 , and $53 \mathrm{~mL} \cdot \mathrm{yr}^{-1}$, respectively. For those with past asthma, the corresponding FEV1 decline values were 41, 42 and $75 \mathrm{~mL}$. $\mathrm{yr}^{-1}$, respectively. For those with current asthma, FEV1 decline values were 20,53 and $87 \mathrm{~mL} \cdot \mathrm{yr}^{-1}$, respectively.

\section{Chronic bronchitis and chronic airflow limitation}

"Feels worse" was significantly related to 1972 chronic bronchitis (odds ratio $=4.09,95 \%$ CI 2.85-5.85), an association that remained similar after exclusion of those with a history of asthma (odds ratio $=3.68,95 \%$ CI 2.43-5.58). "Feels worse" was significantly related to 1972 chronic airflow limitation for both definitions used. Considering FEV $1<65 \%$ pred, the odds ratio was $3.56,95 \%$ CI $2.23-5.69$ and for $\leq 75 \%$ pred, the odds ratio was $2.45,95 \%$ CI 1.65-3.66. Associations of "feels worse" to chronic airflow limitation remained after exclusion of those with a history of asthma for both definitions, and were still significant for FEV $1 \leq 65 \%$ pred after exclusion of subjects with a history of asthma or chronic bronchitis (odds ratio $=2.37,95 \%$ CI $1.08-5.21$ ) or after exclusion of those with a history of asthma, chronic bronchitis, cardiac disease or hypertension (odds ratio $=2.50,95 \%$ CI 1.02-6.13). "Feels better" was significantly related to chronic airflow limitation, but not to chronic bronchitis. The association of "feels better" with chronic airflow limitation remained after exclusion of asthmatics (for FEV1 $\leq 65 \%$ pred, odds ratio $=2.91$, 95\% CI $1.00-8.48$ and for FEV $1 \leq 75 \%$ pred, odds ratio $=2.70,95 \%$ CI $1.20-6.06$ ).

\section{Dyspnoea}

"Feels worse" significantly increased with the grade of dyspnoea (a classical symptom of disease-specific quality-of-life scales in respiratory health) with a prevalence of $14,29,42,46$ and $100 \%$ for the 505 grade 1 , 248 grade 2, 43 grade 3,22 grade 4 and 4 grade 5 subjects, respectively. In subjects with moderate dyspnoea (grade 2), "feels worse" was significantly $(\mathrm{p}<0.001)$ related to FEV1 (fig. 3). After exclusion of subjects with poor tracings, "feels worse" remained significantly related to FEV1 $(-0.07$ versus $-0.71 ; \mathrm{p}<0.001)$ in subjects with moderate dyspnoea. Exclusion of asthmatics did not change these results. Therefore, a reported deterioration in the previous 10 yrs adds further information to dyspnoea as a predictor of current FEV1. Lack of response to the self-assessment of respiratory change was more frequent among those with dyspnoea grade 3 or more independent of age, but lung function values were similar both in those who answered and those who did not. 


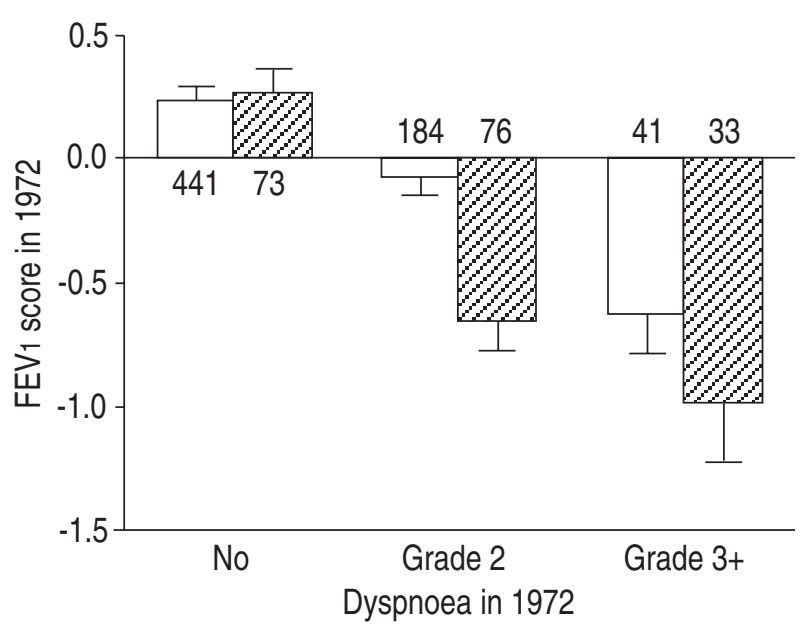

Fig. 3. - Age and height-adjusted forced expiratory volume in one second (FEV1) score in 1972 according to dyspnoea and self-assessment of respiratory deterioration. The $\mathrm{p}$-values in a model with two main effects, dyspnoea and "feels worse", with the interaction term dyspnoea $\times$ feels worse: were $<0.001$ for dyspnoea, 0.001 for "feels worse" and 0.004 for the interaction term. $\square$ : does not feel worse; $\square$ : feels worse. Values on the abscissa are the numbers of subjects.

Table 3. - Predictive value of reported respiratory deterioration between 1960 and 1972 ("feel worse") on 1972-1992 deaths

\begin{tabular}{lrl}
\hline & $\begin{array}{c}\text { Deaths } \\
\mathrm{n}\end{array}$ & \multicolumn{1}{c}{$\begin{array}{l}\text { Rate ratio } \\
(95 \% \mathrm{CI})\end{array}$} \\
\hline All causes & 418 & $1.27(1.01-1.59)^{\dagger}$ \\
Cancers (ICD 140-239) & 125 & $1.11(0.72-1.70)$ \\
Lung cancer (ICD 162) & 30 & $1.67(0.76-3.65)$ \\
Circulatory (ICD 390-459) & 115 & $1.71(1.12-2.60)^{* *}$ \\
Digestive (ICD 520-579) & 24 & $1.41(0.56-3.56)$ \\
Respiratory (ICD 460-519) & 17 & $1.84(0.65-5.24)$ \\
Ill-defined (ICD 780-799) & 15 & $0.31(0.04-2.38)$ \\
External causes & 18 & $1.10(0.32-3.83)$ \\
\hline
\end{tabular}

All causes are known up to at least the end of 1992 (412 deaths up to 1992 and six deaths in 1993). Specific causes concerned only deaths to the end of 1991 (see methods). ICD: 8th and 9th revisions of the International Classification of Diseases. Specific causes with less than 10 deaths are not presented. $:$ Cox's proportional hazards regression models including age; ${ }^{\dagger} \mathrm{p}=0.04 ; * *$ : $\mathrm{p}=0.01$.

\section{Predictive validity (mortality)}

"Feels worse" in 1972 was a significant predictor of all causes of death during the subsequent 20 yrs. In a Cox's model including age and "feels worse", the rate ratio of all causes of death associated with "feels worse" was 1.27 , with 95\% CI 1.01-1.59 ( $\mathrm{p}=0.04)$. A Cox's model with age and 1972 smoking habits gave rate ratios of 1.47 (95\% CI 0.93-2.23) for exsmokers versus nonsmokers, 1.45 (95\% CI 0.96-2.18) for moderate smokers versus nonsmokers and 2.44 (95\% CI 1.623.69) for heavy smokers versus nonsmokers. A Cox's model with age and occupational exposure gave a rate ratio of 1.30 (95\% CI 1.05-1.60) for those with exposure versus those without. In a model containing age, smoking habits, occupational exposure and "feels worse", the rate ratio of "feels worse" was 1.23 (95\% CI 0.97-1.56). "Feels worse" was a significant predictor of cardiovascular death with a rate ratio of 1.71 (table 3 ). Although nonsignificant, (17 deaths only), the highest rate ratio
(1.84) was observed for respiratory death. For comparative purposes, it can be noted that in models with age and smoking habits for specific causes of death, the rate ratio of heavy smoking was 2.76 for cancer (not computable for lung cancer, as none of those who died of lung cancer were nonsmokers), 1.69 for cardiovascular deaths and 6.58 for respiratory causes. Lack of response to the self-assessment of respiratory change was independent of age, significantly related to death with a rate ratio for all causes of 1.48 (95\% CI, 1.11-1.97). "Feels better" was unrelated to survival.

\section{Discussion}

Results gathered over a $30 \mathrm{yr}$ period in a cohort of workers in the Paris area show that a simple question on self-assessment of 12 yrs of respiratory change meets both criteria of concurrent and predictive validity. Subjective assessment of respiratory health deterioration was significantly related to steeper 12 yr FEV1 decline and this association remained after adjustment for FEV1 levels. Subjective assessment of respiratory changes related to risk factors of FEV1 decline. Self assessment of deterioration predicted death in the subsequent years. In conclusion, subjective assessment of respiratory health changes provides valid information on health status. Perceived health change that include assessment of longterm changes ( $10 \mathrm{yrs}$ ) provides information complementary to that of objective measures and current dyspnoea, a classical symptom used in such scales.

Perceived respiratory deterioration was related to current lung function, dyspnoea, chronic bronchitis and asthma, which shows that subjects were able to assess respiratory health. The observed effect size (half a standard deviation) corresponds, at the group level, to a strong association of reported deterioration and FEV1 level. This is stronger than the rather weak associations reported between lung function and quality of life scales, especially generic scales [7, 24-27] in other studies, conducted mostly in rather homogeneous groups of patients. Few respiratory epidemiological surveys have included health-related quality-of-life data [28, 29]. Dyspnoea, a classical item of quality-of-life scales provides information in addition to FEV1 [30]. Perceived deterioration was related to FEV1 independent of dyspnoea, showing that such subjective measures provide information other than the classical symptoms of dyspnoea. Such information may help clinicians to delineate those with an ongoing process among subjects with mild dyspnoea.

The most important result is the demonstration of the ability of subjects to perceive long-term changes. Besides the expected association of perceived deterioration to current lower lung function and dyspnoea, perceived deterioration did relate to lung function changes independent of FEV1 level. Two criteria for responsiveness [31] are fulfilled: the association of much greater changes (improvement or deterioration) for subjects known to have a variable respiratory status (asthmatics) compared to more stable subjects (nonasthmatics) and the association with FEV1 decline independent of FEV1 levels even in nonasthmatics. Except among asthmatics, perceived improvement was not related to slower 
FEV1 decline. The present results are consistent with a steeper FEV1 decline observed among asthmatics than among nonasthmatics [32]. They further show that the asthmatics report in the long-term greater subjective variability than nonasthmatics. Such greater variability was only described for the short-term until now. Furthermore, long-term subjective deterioration or improvement correlated with objective lung function measures.

Perceived changes related to risk factors of lung function decline. These results extend previous observations in the same population on the effect of smoking and occupational exposure on lung function decline [11, $12,19]$ by the demonstration of associations of these risk factors with perceived changes. As known risk factors of steep FEV1 decline were related to "feels worse", studying factors of "feels worse" through cross-sectional studies may allow the generation of hypotheses on potential risk factors of FEV1 decline. Reported improvement after quitting smoking was evident, despite the difficulty of exhibiting functional improvement [19]. Although it may be possible that reported improvement by exsmokers is due to the satisfaction of subjects of having quit, this is unlikely to be the sole explanation as improvement was reported to be independent of the time elapsed since quitting, and deterioration was reported by those who quit in the last year. Studying the long-term effects of prescriptions of $\beta$ agonists and steroids in the same population showed concordant results considering subjective assessment, FEV1 decline and subsequent survival [33]. Taken in association with quitting smoking, this suggests that perceived long-term change has evaluative properties.

Subjects gave age-adjusted subjective assessments of their clinical status, when asked. Furthermore, the lack of association of subjective data with socio-occupational class, a factor related to FEV1 decline [12] and mortality [34], in this population suggests that subjects spontaneously take their sociocultural peers as a reference group. It is possible that, more generally, perceived health measures may be "adjusted" on sociocultural factors. In the assessment of relations of risk factors to disease, consideration of perceived health measures may be an indirect means of adjustment on potential unmeasured sociocultural confounders.

Asking a patient to assess change is different from the evaluation of that change through two cross-sectional measures of perceived health status. The subject adds his/her own value of what a meaningful change represents. Until now, global rating $[9,10]$ change has only been used on a short-term basis (since last visit) to assess a clinically important difference. This is a method of determining the minimum differences among various items in disease specific scales. Results suggest that global rating changes are valid measurements, which may be analysed and applied more extensively.

Predictive validity was evidenced by associations of reported respiratory deterioration with death from all causes in the subsequent 20 yrs. Results extend the predictive value of poor perceived health in relation to all causes mortality [35] and specific causes [36]. Comorbid conditions may have influenced the answers on perceived respiratory health changes, but the association of perceived deterioration with chronic airflow limitation remained after exclusion of asthma, chronic bronch- itis or cardiac disease. Consistent with good respiratory specificity was the strong association of perceived deterioration with respiratory deaths. No check of the validity of death certificates was possible, as the causes of death were only obtained by cross-referencing two data bases, as explained in the methods section. A potential bias is unlikely to be differential; however, it can only decrease the associations of specific causes with the report of perceived deterioration.

Results obtained in a working population may not be valid in other groups and need to be replicated. This may be relatively easy for FEV 1 decline by the inclusion of subjective assessment in ongoing longitudinal studies. Of particular interest would be surveys with more than two lung function measures, which permit a more accurate adjustment for current level. This could only be done in the present study by considering the midpoint FEV1 to avoid the phenomenon of regression towards the mean. The simplicity of the subjective measurement variable may explain the observation that more than $90 \%$ of the subjects were able to answer the question. Nonresponders were anticipated: elderly, asthmatics, dyspnoeics. In future studies, however, more detailed [9] quantification of long-term changes should be attempted.

It is important to avoid overinterpreting these findings. The present study showed differences between groups with different risk factors or treatments. It did not demonstrate that reported long-term change is a valid tool for evaluating interventions. All the associations studied here were observational. Retrospective data, especially those regarding change, are subject to bias, which may be more important in intervention studies. The present study is based on retrospective assessment of change (i.e. a direct transitional index). Successive cross-sectional observations allow the computation of another type of transitional index, through prospective data. It would be interesting to compare both types of transitional index of perceived health (perception of change and change in perception) to objective measures in other observational and interventional types of studies.

Dyspnoea, an important respiratory symptom, is already a classical symptom in quality-of-life scales. Results suggest that the inclusion of items regarding long-term (10 yrs) change in respiratory health in such scales should be evaluated. Whether or not the perception of health change is a more important factor than perceived health status in healthcare, demand or treatment compliance may be topics for further research. It is recognized that single item measures of a dimension as complicated as the self perception of health may lack sensitivity, however their utility should not be ignored. Easy to administer and analyse, they have a very high completion rate. While we would not claim "construct" validity [37] for this single item, the results have shown both concurrent and predictive validity with standardized, classical markers.

In conclusion, the present results suggest that long-term changes regarding respiratory health status may be validly reported by subjects. It remains to be determined whether such findings hold true for other diseases. The present results may have implications for both epidemiological surveys and clinical settings. Perceived health status and perceived health changes are not surrogate 
markers for objective data, but provide additional, complementary and valid information.

Acknowledgements: The authors would like to thank D. Brille for the design of the questions at a time when perceived health was rarely considered in scientific reports, J. Lellouch for helpful discussions, F. Hatton and E. Michel (INSEAM SC8, Institut National de la Santé et de la Recherche Médicale death causes department) for help on the analysis on causes of death.

\section{References}

1. Bergner M. Quality of life, health status, and clinical research. Med Care 1989; 27: S148-S156

2. Patrick DL, Deyo RA. Generic and disease-specific measures in assessing health status and quality of life. Med Care 1989; 27: S217-S232.

3. Juniper EF, Guyatt GH, Ferrie PJ, Griffith LE. Measuring quality of life in asthma. Am Rev Respir Dis 1993; 147: 832-838.

4. Jones PW. Quality of life measurement for patients with diseases of the airways. Thorax 1991; 46: 676-682.

5. Marks GB, Dunn SM, Woolcock. A scale for the measurement of quality of life in adults with asthma. $J$ Clin Epidemiol 1992; 45: 461-472.

6. Guyatt G, Feeny D, Patrick D. Issues in quality of life measurement in clinical trials. Cont Clin Trials 1990; 12: $81 \mathrm{~S}-90 \mathrm{~S}$.

7. van Schayck CP, Tutten-van Mölken MPMH, van Doorslaer EKA, Folgering H, van Weel C. Two-year bronchodilator treatment in patients with mild airflow obstruction. Contradictory effects on lung function and quality of life. Chest 1992; 102: 1384-1391.

8. Guyatt GH, Berman LB, Townsend M, Pugsley SO, Chambers LW. A measure of quality of life for clinical trials in chronic lung disease. Thorax 1987; 42: 773778.

9. Jaeschke R, Singer J, Guyatt GH. Measurement of health status. Ascertaining the Minimal Clinically Important Difference. Cont Clin Trials 1989; 10: 407-416.

10. Juniper EF, Guyatt GH, Willan A, Griffith LE. Determining a minimal important change in a disease-specific quality of life questionnaire. J Clin Epidemiol 1994; 47: 81-87.

11. Kauffmann F, Drouet D, Lellouch J, Brille D. Twelve years spirometric changes among Paris area workers. Int J Epidemiol 1979; 8: 201-212.

12. Kauffmann F, Drouet D, Lellouch J, Brille D. Occupational exposure and 12-year spirometric changes among Paris area workers. Br J Industr Med 1982; 39: 221-232.

13. Brille D, Casula D, Lende R Van der et al. Commentaires relatifs au questionnaire pour l'étude de la bronchite chronique et de l'emphysème (1967) Luxembourg: Commission of the European Communities, 1971 (Coil Hyg Med Travail, $\left.n^{\circ} 14\right)$.

14. Becklake MR. Epidemiology of spirometric test failure. Br J Industr Med 1990; 47: 73-74.

15. Schwartz D, Lellouch J. Explanatory and pragmatic attitudes in therapeutic trials. J Chron Dis 1967; 20: 637-648.

16. Drouet D, Kauffmann F, Brille D, Lellouch J. Valeurs spirographiques de référence. Modèles mathématiques et utilisation pratique. Bull Europ Physiopathol Respir 1980; 16: 745-767.

17. Oldham PD. A note on the analysis of repeated measurements of the same subjects. J Chron Dis 1962; 15: 969-977.
18. Fletcher CM, Peto R, Tinker C, Speizer FE. The Natural History of Chronic Bronchitis and Emphysema. Oxford, Oxford University Press, 1976.

19. Kauffmann F, Querleux E, Drouet D, Lellouch J, Brille D. Evolution du VEMS en 12 ans et tabagisme chez 556 travailleurs de la région parisienne. Bull Europ Physiopathol Respir 1979; 15: 723-737.

20. Quanjer PhH (ed), Dalhhuisjsen A, Van Zomeren BC. Summary equations of reference values. Standardized lung function testing. Bull Eur Physiopathol Respir 1983; 19 (Suppl.): 45-51.

21. Snedecor GW, Cochran WG. Statistical Methods. Ames, The Iowa State University Press, 1967.

22. Cox DR, Oakes D. Analysis of Survival Data. London, Chapman \& Hall, 1984.

23. SAS technical report P-229, SAS/STAT software: the PHREG procedure, version 6.07, Cary, N.C.: SAS Institute, 1992.

24. Schrier AC, Dekker PW, Kaptein AA, Dijkman JH. Quality of life in elderly patients with chronic nonspecific lung disease seen in family practice. Chest 1990; 98: 894-899.

25. Curtis JR, Deyo RA, Hudson LD. Health-related quality of life among patients with chronic obstructive pulmonary disease. Thorax 1994; 49: 162-170.

26. Jones PW, Quirk FH, Baveystock CM, Littlejohns P. A self-completed measure of health status for chronic airflow limitation. The St Georges Respiratory Questionnaire. Am Rev Respir Dis 1992; 145: 1321-1327.

27. Mahler DA, Tomlinson D, Olmstead EM, Tosteson ANA, O'Connor GT. Changes in dyspnea, health status, and lung function in chronic airway disease. Am J Respir Crit Care Med 1995; 151: 61-65.

28. Marks GB, Dunn SM, Woolcock AJ. A scale for the measurement of quality of life in adults with asthma. $J$ Clin Epidemiol 1992; 45: 461-472.

29. Kennedy SM, Desjardins A, L, Kassam A, Ricketts M, Chan-Yeung M. Assessment of respiratory limitation in activities of daily life among retired workers. Am J Respir Crit Care Med 1994; 149: 575-583.

30. Vestbo J, Knudsen KM, Rasmussen FV. Should we continue using questionnaires on breathlessness in epidemiologic surveys. Am Rev Respir Dis 1988; 137: $1114-1118$.

31. Jaeschke R, Guyatt GH. How to develop and validate a new quality of life instrument. In: Spilker B, ed. Quality of Life assessments in clinical trials. New York, Raven Press, 1990: pp. 47-57.

32. Ulrik C, Lange P. Decline of lung function in adults with bronchial asthma. Am J Respir Crit Care Med 1994; 150: 629-634.

33. Fuhrman C, Ernst P, Kauffmann F. Long-term effects of therapy on respiratory health. Eur Respir J 1996; 9; 436-443.

34. Annesi I, Kauffmann F. Is respiratory mucus hypersecretion really an innocent disorder? A 22-year mortality survey of 1061 working men. Am Rev Respir Dis 1986; 134: 688-693.

35. Mossey JM, Shapiro E. Self-rated health: a predictor of mortality among the elderly. Am J Publ Health 1982; 72: 800-808.

36. Pijls LTJ, Feskens EJM, Kromhout D. Self-rated health, mortality, and chronic diseases in elderly men. The Zutphen study, 1985-1990. Am J Epidemiol 1993; 138: 840-848.

37. Nunnally JC. Psychometric Theory. New York, McGraw Hill, 1978. 